\title{
Genetic correlation of traits measured by ultrasound at yearling and 18 months of age in Nellore beef cattle
}

\author{
M.J. Yokoo ${ }^{\text {a }}$, R.B. Lôbo ${ }^{\text {b }}$, C.U. Magnabosco ${ }^{\text {c }}$, G.J.M. Rosa ${ }^{\text {d, S. Forni }}{ }^{\text {e }}$, R.D. Sainz ${ }^{\text {f }}$, \\ L.G. Albuquerque ${ }^{\text {g,* }}$ \\ a Embrapa Southern Region Animal Husbandry, Center of Livestock Research of South Brazilian Fields (CPPSUL), Bagé, RS 96401-970, Brazil \\ ${ }^{\mathrm{b}}$ Researcher affiliated with Associação Nacional de Criadores e Pesquisadores, Ribeirão Preto, SP 14020-230, Brazil \\ c Embrapa Cerrados, Planaltina, DF 73310-970, Brazil \\ d Department of Dairy Science, University of Wisconsin, Madison, WI 53706, USA \\ e Dow AgroSciences, Indianapolis, IN 46268, USA \\ ${ }^{\mathrm{f}}$ Department of Animal Science, University of California, Davis, CA 95616-8521, USA \\ ${ }^{\mathrm{g}}$ Department of Animal Science, São Paulo State University (UNESP), Jaboticabal, SP 14884-900, Brazil
}

\section{A R T I C L E I N F O}

\section{Article history:}

Received 4 March 2015

Received in revised form

30 June 2015

Accepted 4 July 2015

\section{Keywords:}

Bayesian inference

Carcass

Genetic parameters

Gibbs sampling

Heritability

\begin{abstract}
A B S T R A C T
The objective of this study was to estimate genetic parameters for carcass traits measured by ultrasound at yearling $(\mathrm{Y})$ and 18 months of age (post-yearling, $\mathrm{PY}$ ) in order to identify the most appropriate age for the measurement of these traits used for the selection of Nellore beef cattle. In addition, genetic correlations were estimated between these carcass traits and between carcass and other economically important traits such as scrotal circumference, weight, hip height at 18 months of age, age at first calving, and first calving interval (FCI). The carcass traits were longissimus muscle area (LMA), backfat thickness (BF), and rump fat thickness (RF) recorded at two different ages (Y and PY). Gibbs sampling was applied to estimate the genetic parameters using multiple trait animal model. The estimates of posterior heritabilities and standard deviations (SD) for the carcass traits were $0.46, S D=0.06$ (LMA_Y), $0.42, S D=0.07$ (BF_Y), 0.60, SD =0.09 (RF_Y), 0.33, SD =0.06 (LMA_PY), 0.59, SD $=0.08$ (BF_PY), and $0.55, \mathrm{SD}=0.09$ (RF_PY). The genetic parameters obtained in this study suggest the existence of genetic variability in all carcass traits at both ages. Hip height was negatively correlated with BF_PY and RF_PY, indicating that selection of taller animals may lead to animals that will deposit less subcutaneous fat. Selection for growth and carcass traits will not affect FCI, except for an increase in BF_PY which will increase FCI in the long term, possibly due to a correlated response, once the genetic correlation is moderate $(0.40, \mathrm{SD}=$ $0.17)$, and the posterior heritability for $\mathrm{FCI}$ was relatively low $(0.11, \mathrm{SD}=0.03)$. The traits LMA, BF and RF measured at $\mathrm{Y}$ and at $\mathrm{PY}$ are practically the same traits since the genetic correlation are $0.83(\mathrm{SD}=0.06)$, $0.94(\mathrm{SD}=0.02)$ and $0.72(\mathrm{SD}=0.07)$, respectively. In conclusion, ultrasound carcass traits should respond rapidly to selection and can be recorded only in one age, at Y or at PY. Furthermore, there is no need to include the two subcutaneous fat thickness measures (BF and RF) in selection criteria since they are highly genetic correlated. Genetic progress for these carcass traits can be achieved without affecting the breeding value of animals for other economic traits, since the most of genetic correlation estimates are favorable and of low magnitude.
\end{abstract}

(c) 2015 Elsevier B.V. All rights reserved.

\section{Introduction}

An efficient way to improve the quality of beef is the use of ultrasound technology for improving the carcass traits. With this technology it is possible to evaluate the carcass merit without the need for slaughtering the animal and does not leave residues in the meat (Perkins et al., 1992a, 1992b). Breeding values for carcass

\footnotetext{
* Corresponding author.

E-mail address: lgalb@fcav.unesp.br (L.G. Albuquerque).
}

traits, measured by ultrasound, have been used to selecting for muscling, intramuscular fat and subcutaneous fat thickness (Wilson, 1992; Wilson et al., 1993; Herring et al., 1998).

In taurine animals, carcass traits measured by ultrasound are generally obtained at ages close to yearling (Beef Improvement Federation, 2002). Hassen et al. (2004), who studied Angus cattle, reared in temperate regions, using random regression models and including 36 age points ranging from 6 to 14 month of age, reported a higher genetic variability for longissimus muscle area (LMA) at 12 months of age. Studies estimating genetic parameters 
in zebu breeds reared in tropical regions are scarce. Yokoo et al. (2008, 2009) and Lima Neto et al. (2009) studying LMA and subcutaneous fat thickness estimated heritability coefficients of low to high magnitude, ranging from 0.05 to 0.55 , for Nellore and Guzera animals at 18 months of age (post-yearling, PY).

Usually, at 18 months of age, animals reared on pasture in tropical areas present low subcutaneous fat thickness in the region of the ribs, a fact impairing the demonstration of genetic differences between animals (Yokoo et al., 2008). However, the number of animals in the herd often decreases after this age since breeders discard animals at weaning, yearling and 18 months of age. In addition, the measurement of carcass traits by ultrasound becomes more difficult with increasing age since the arched position of the ribs changes and the transverse apophysis grows. This impairs the exact coupling of the probe and the collection of images for the evaluation of LMA and backfat thickness (BF), which are measured between 12th and 13th rib. Another obstacle is that the LMA of older animals, which are generally large, does not fit on the ultrasound screen, thus prejudicing its precise measurement. Moreover, rump fat (RF) genetic differences are possible higher at younger ages, since RF starts to be deposited earlier than BF in Nellore (Yokoo et al., 2008). Therefore, other ages prior to 18 months of age might be studied. If genetic variability exists in carcass traits measured by ultrasound at ages close to yearling and if the genetic correlations between these traits and other economically important traits are favorable, the evaluation of animals at ages close to yearling would be an alternative to anticipate the decision-making about selection for these traits.

In view of possible market changes and considering the long period of time necessary for the occurrence of genetic changes due to selection, studies investigating the most appropriate age for the collection of carcass quality traits are required. Therefore, the objectives of the present study were to estimate genetic and phenotypic parameters for carcass traits measured by real time ultrasound at yearling and 18 months of age and to evaluate genetic correlations between these ultrasound carcass measures and between these traits and other economically important traits. These results will be of fundamental importance for the elaboration and implementation of genetic breeding programs targeting these traits.

\section{Material and methods}

The present study was conducted on Nellore animals belonging to an existing database from herds of breeders participating in the Brazilian Nellore Breeding Program. On-farm data collection was conducted according to routine management procedures and conformed to the guidelines of NRC (1996).

\subsection{Traits}

The carcass traits measured by real time ultrasound were collected from male and female animals between 2002 and 2004 on 10 farms located in the states of São Paulo, Mato Grosso do Sul, Mato Grosso, Minas Gerais, Paraná, and Goiás. These traits measured by ultrasound were longissimus muscle area (LMA), backfat thickness (BF), and rump fat thickness (RF). The ultrasound images were acquired with an ALOKA $500 \mathrm{~V}$ apparatus equipped with a $3.5 \mathrm{MHz}$ linear probe $(17.2 \mathrm{~cm})$ and an acoustic coupler and saved using an image capture system (Blackbox, Biotronics, Inc., Ames, IA, USA). Next, these images were interpreted by the laboratory responsible for the quality of the data (Aval Serviços Tecnológicos $\mathrm{S} / \mathrm{C}$ ) using the Biosoft Toolbox software (Biotronics, Inc.). Appropriate Ultrasound Guidelines Council (UGC) methodology (http:// www.ultrasoundbeef.com/), described in the Beef Improvement
Federation Guidelines (Beef Improvement Federation (BIF) 1996) was used. Further details about the ultrasound images measurements can be found in Yokoo et al. (2008). The animals were also weighed on the occasion of collection of the ultrasound data.

The ultrasound carcass traits and weight were collected at two different ages. The first measurement (yearling, Y) was performed on 1279 animals with a mean age of 370 days (329-450 days) belonging to nine farms, and the second measurement was obtained at 18 months of age (post-yearling, PY) from 2776 animals with a mean age of 570 days ( $480-629$ days) belonging to 10 farms. The data file contained 802 animals with measurements at the two ages (repeated measures for the same animal). Hip height $(\mathrm{HH})$ was measured on the occasion of the ultrasound measurements at 18 months of age, directly over the hooks (hip bones) with the animal standing on a level surface, in accordance with the Beef Improvement Federation Guidelines (Beef Improvement Federation (BIF) 2002).

In addition to the ultrasound carcass traits, $\mathrm{HH}$ and weight, the following reproductive traits were also evaluated: age at first calving (AFC) calculated as the difference between the date of first calving and the date of birth of 7648 dams in days, and first calving interval ( $\mathrm{FCI}$ ) calculated as the difference between the first and second calving in days of 5764 dams. These female reproductive traits were obtained from four herds and refer to dams born between 1977 and 2003. The existence of birth along the year was also evaluated, although most farms adopt a long breeding season during the rainy season. Similarly, 5695 measurements of scrotal circumference adjusted to 450 days of age (SC450) were obtained from the data file of these farms for all male animals born between 1998 and 2003 in the 10 herds studied. Age-standardized SC450 were obtained as in Beef Improvement Federation (2002). There were 297 animals measured for all ultrasound carcass traits and AFC and FCI (repeated measures for the same animal), consequently, correlation estimates were obtained mainly through relationship matrix (Table 1).

\subsection{Data}

The contemporary group (CG) was defined as animals of the same farm, sex (except for SC450, AFC and FCI), season and year of birth, and management group. Animals whose measurements were 3 standard deviations above or below the average of their respective CG, were eliminated, as were CGs including only sons of the same sire and CGs with less than three animals. Table 1 shows

Table 1

Description of the data file of Nellore cattle.

\begin{tabular}{lcclcc}
\hline Trait & $n$ & Mean (SD) & $n$ of sires & $n$ of dams & $n$ of CG \\
\hline LMA_Y, cm ${ }^{2}$ & 1279 & $46.95(10.77)$ & 164 & 1066 & 110 \\
BF_Y, mm & 1204 & $1.95(1.11)$ & 160 & 999 & 121 \\
RF_Y, mm & 1197 & $3.01(1.88)$ & 160 & 993 & 121 \\
W_Y, kg & 2358 & $268.97(64.09)$ & 227 & 2079 & 204 \\
LMA_PY, cm ${ }^{2}$ & 2776 & $48.05(8.36)$ & 231 & 2552 & 243 \\
BF_PY, mm & 2581 & $1.87(1.07)$ & 226 & 2397 & 253 \\
RF_PY, mm & 2570 & $2.95(1.94)$ & 226 & 2384 & 252 \\
W_PY, kg & 2966 & $339.69(65.98)$ & 236 & 2683 & 302 \\
HH, cm & 2356 & $136.06(5.04)$ & 226 & 2308 & 250 \\
SC450, mm & 5695 & $245.87(30.22)$ & 386 & 4109 & 188 \\
AFC, days & 7648 & $1117(161.98)$ & 485 & 6785 & 706 \\
FCI, days & 5764 & $466(123.80)$ & 439 & 4437 & 656 \\
\hline
\end{tabular}

$n=$ number of animals; $\mathrm{SD}=$ standard deviation; $\mathrm{CG}=$ contemporary group. LMA_Y and LMA_PY=longissimus muscle area at 12 and 18 months of age, respectively; BF_Y and BF_PY=backfat thickness at 12 and 18 months of age, respectively; RF_Y and RF_PY =rump fat thickness at 12 and 18 months of age, respectively; W_Y and W_PY=live weight at 12 and 18 months of age, respectively; $\mathrm{HH}=$ hip height measured at 18 months of age; SC450 = scrotal circumference adjusted to 450 days of age; $\mathrm{AFC}=$ age at first calving; $\mathrm{FCI}=$ first calving interval. 
Table 2

Estimates of heritability (diagonal) and genetic (above the diagonal) and phenotypic (below the diagonal) correlations between the traits studied obtained for Nellore cattle.

\begin{tabular}{|c|c|c|c|c|c|c|c|c|c|c|}
\hline Trait & LMA_Y & BF_Y & RF_Y & $W_{-} Y$ & LMA_PY & BF_PY & RF_PY & W_PY & $\mathrm{HH}$ & SC450 \\
\hline \multirow[t]{2}{*}{ LMA_Y } & $0.46 \pm 0.06^{\mathrm{a}}$ & $0.07 \pm 0.13$ & $-0.06 \pm 0.16$ & $0.65 \pm 0.07$ & $0.83 \pm 0.06$ & $-0.05 \pm 0.13$ & $0.12 \pm 0.14$ & $0.57 \pm 0.09$ & $0.18 \pm 0.12$ & $0.32 \pm 0.11$ \\
\hline & 0.33 to $0.58^{\mathrm{b}}$ & -0.21 to 0.32 & -0.38 to 0.25 & 0.50 to 0.79 & 0.71 to 0.94 & -0.30 to 0.19 & -0.15 to 0.40 & 0.39 to 0.74 & -0.04 to 0.43 & 0.10 to 0.53 \\
\hline \multirow[t]{2}{*}{$\mathrm{BF}_{-} \mathrm{Y}$} & $0.17 \pm 0.04$ & $0.42 \pm 0.07$ & $0.73 \pm 0.09$ & $0.47 \pm 0.10$ & $0.10 \pm 0.17$ & $0.94 \pm 0.02$ & $0.76 \pm 0.08$ & $0.53 \pm 0.11$ & $0.27 \pm 0.17$ & $0.40 \pm 0.17$ \\
\hline & 0.10 to 0.24 & 0.27 to 0.56 & 0.56 to 0.87 & 0.28 to 0.67 & -0.26 to 0.42 & 0.91 to 0.97 & 0.60 to 0.90 & 0.31 to 0.73 & -0.09 to 0.57 & 0.03 to 0.69 \\
\hline \multirow[t]{2}{*}{ RF_Y } & $0.13 \pm 0.04$ & $0.56 \pm 0.03$ & $0.60 \pm 0.09$ & $0.19 \pm 0.13$ & $-0.12 \pm 0.13$ & $0.79 \pm 0.08$ & $0.72 \pm 0.07$ & $0.07 \pm 0.14$ & $-0.17 \pm 0.15$ & $-0.02 \pm 0.12$ \\
\hline & 0.06 to 0.21 & 0.51 to 0.62 & 0.43 to 0.79 & -0.05 to 0.44 & -0.37 to 0.14 & 0.64 to 0.92 & 0.57 to 0.84 & -0.24 to 0.31 & -0.47 to 0.11 & -0.26 to 0.21 \\
\hline \multirow[t]{2}{*}{$W_{-} \mathrm{Y}$} & $0.57 \pm 0.02$ & $0.31 \pm 0.03$ & $0.27 \pm 0.03$ & $0.52 \pm 0.05$ & $0.58 \pm 0.08$ & $0.22 \pm 0.11$ & $0.24 \pm 0.07$ & $0.90 \pm 0.03$ & $0.72 \pm 0.06$ & $0.27 \pm 0.05$ \\
\hline & 0.53 to 0.61 & 0.25 to 0.37 & 0.20 to 0.33 & 0.41 to 0.62 & 0.41 to 0.75 & 0.01 to 0.42 & 0.10 to 0.37 & 0.84 to 0.95 & 0.59 to 0.83 & 0.17 to 0.35 \\
\hline \multirow[t]{2}{*}{ LMA_PY } & $0.72 \pm 0.02$ & $0.17 \pm 0.04$ & $0.15 \pm 0.07$ & $0.50 \pm 0.02$ & $0.33 \pm 0.06$ & $0.22 \pm 0.13$ & $0.19 \pm 0.13$ & $0.59 \pm 0.08$ & $0.22 \pm 0.15$ & $0.20 \pm 0.11$ \\
\hline & 0.68 to 0.76 & 0.09 to 0.25 & 0.02 to 0.27 & 0.46 to 0.54 & 0.21 to 0.45 & -0.04 to 0.46 & -0.09 to 0.43 & 0.42 to 0.74 & -0.07 to 0.49 & -0.03 to 0.40 \\
\hline \multirow[t]{2}{*}{ BF_PY } & $0.06 \pm 0.04$ & $0.72 \pm 0.03$ & $0.62 \pm 0.04$ & $0.20 \pm 0.03$ & $0.16 \pm 0.03$ & $0.59 \pm 0.08$ & $0.67 \pm 0.08$ & $0.21 \pm 0.11$ & $-0.38 \pm 0.12$ & $0.11 \pm 0.10$ \\
\hline & -0.02 to 0.14 & 0.67 to 0.77 & 0.53 to 0.69 & 0.14 to 0.25 & 0.11 to 0.21 & 0.44 to 0.75 & 0.51 to 0.81 & 0.01 to 0.42 & -0.62 to -0.17 & $-0 . \overline{1} 1$ to 0.28 \\
\hline \multirow[t]{2}{*}{ RF_PY } & $0.09 \pm 0.05$ & $0.47 \pm 0.04$ & $0.64 \pm 0.03$ & $0.11 \pm 0.04$ & $0.13 \pm 0.03$ & $0.59 \pm 0.02$ & $0.55 \pm 0.09$ & $0.16 \pm 0.11$ & $-0.32 \pm 0.05$ & $0.12 \pm 0.10$ \\
\hline & -0.01 to 0.18 & 0.39 to 0.54 & 0.56 to 0.69 & 0.04 to 0.17 & 0.08 to 0.18 & 0.56 to 0.63 & 0.36 to 0.73 & -0.06 to 0.37 & -0.40 to -0.22 & -0.07 to 0.32 \\
\hline \multirow[t]{2}{*}{ W_PY } & $0.47 \pm 0.02$ & $0.27 \pm 0.03$ & $0.21 \pm 0.04$ & $0.79 \pm 0.01$ & $0.52 \pm 0.02$ & $0.24 \pm 0.03$ & $0.17 \pm 0.03$ & $0.47 \pm 0.05$ & $0.59 \pm 0.06$ & $0.43 \pm 0.09$ \\
\hline & 0.42 to 0.52 & 0.21 to 0.33 & 0.10 to 0.29 & 0.77 to 0.81 & 0.49 to 0.55 & 0.19 to 0.29 & 0.11 to 0.22 & 0.36 to 0.58 & 0.47 to 0.71 & 0.25 to 0.59 \\
\hline \multirow[t]{2}{*}{$\mathrm{HH}$} & $0.23 \pm 0.04$ & $0.10 \pm 0.05$ & $0.05 \pm 0.05$ & $0.55 \pm 0.02$ & $0.15 \pm 0.03$ & $-0.09 \pm 0.05$ & $-0.11 \pm 0.03$ & $0.52 \pm 0.02$ & $0.65 \pm 0.10$ & $-0.05 \pm 0.04$ \\
\hline & 0.16 to 0.31 & 0.00 to 0.19 & -0.05 to 0.14 & 0.51 to 0.59 & 0.09 to 0.22 & -0.18 to -0.01 & -0.16 to -0.05 & 0.48 to 0.56 & 0.47 to 0.91 & -0.12 to 0.02 \\
\hline \multirow[t]{2}{*}{ SC450 } & $0.28 \pm 0.05$ & $0.12 \pm 0.07$ & $0.13 \pm 0.06$ & $0.41 \pm 0.02$ & $0.26 \pm 0.04$ & $-0.06 \pm 0.06$ & $0.00 \pm 0.05$ & $0.38 \pm 0.03$ & $0.10 \pm 0.02$ & $0.58 \pm 0.04$ \\
\hline & 0.17 to 0.38 & -0.02 to 0.26 & 0.01 to 0.24 & 0.37 to 0.44 & -0.18 to 0.33 & -0.16 to 0.08 & -0.10 to 0.11 & 0.33 to 0.44 & 0.06 to 0.15 & 0.49 to 0.65 \\
\hline
\end{tabular}

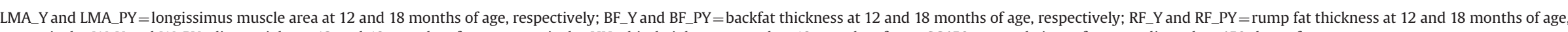

respectively; $\mathrm{W}_{-} \mathrm{Y}$ and $\mathrm{W} \_\mathrm{PY}=$ live weight at 12 and 18 months of age, respectively; $\mathrm{HH}=$ hip height measured at 18 months of age; SC450=scrotal circumference adjusted to 450 days of age.

a Posterior mean \pm standard deviation.

b $95 \%$ High posterior density interval. 
Table 3

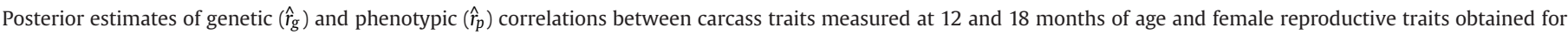
Nellore cattle.

\begin{tabular}{|c|c|c|c|c|c|c|c|}
\hline Trait & & LMA_Y, $\mathrm{cm}^{2}$ & BF_Y, mm & RF_Y, mm & LMA_PY, $\mathrm{cm}^{2}$ & BF_PY, mm & RF_PY, mm \\
\hline \multirow[t]{2}{*}{ AFC, days } & $\hat{r}_{g}$ & $\begin{array}{l}-0.20 \pm 0.16^{\mathrm{a}} \\
-0.51 \text { to } 0.10^{b}\end{array}$ & $\begin{array}{l}0.11 \pm 0.12 \\
-0.13 \text { to } 0.34\end{array}$ & $\begin{array}{l}-0.11 \pm 0.12 \\
-0.35 \text { to } 0.14\end{array}$ & $\begin{array}{l}-0.04 \pm 0.15 \\
-0.32 \text { to } 0.27\end{array}$ & $\begin{array}{l}0.11 \pm 0.10 \\
-0.10 \text { to } 0.28\end{array}$ & $\begin{array}{l}0.14 \pm 0.14 \\
-0.12 \text { to } 0.40\end{array}$ \\
\hline & $\hat{r}_{p}$ & $\begin{array}{l}-0.03 \pm 0.06 \\
-0.14 \text { to } 0.08\end{array}$ & $\begin{array}{l}0.06 \pm 0.06 \\
-0.06 \text { to } 0.17\end{array}$ & $\begin{array}{l}-0.07 \pm 0.05 \\
-0.17 \text { to } 0.03\end{array}$ & $\begin{array}{l}-0.06 \pm 0.08 \\
-0.21 \text { to } 0.08\end{array}$ & $\begin{array}{l}-0.03 \pm 0.03 \\
-0.10 \text { to } 0.04\end{array}$ & $\begin{array}{l}-0.01 \pm 0.05 \\
-0.11 \text { to } 0.10\end{array}$ \\
\hline \multirow[t]{2}{*}{ FCI, days } & $\hat{r}_{g}$ & $\begin{array}{l}0.19 \pm 0.19 \\
-0.16 \text { to } 0.49\end{array}$ & $\begin{array}{l}0.08 \pm 0.17 \\
-0.26 \text { to } 0.36\end{array}$ & $\begin{array}{l}-0.15 \pm 0.23 \\
-0.54 \text { to } 0.31\end{array}$ & $\begin{array}{l}0.01 \pm 0.13 \\
-0.26 \text { to } 0.24\end{array}$ & $\begin{array}{l}0.40 \pm 0.17 \\
0.08 \text { to } 0.70\end{array}$ & $\begin{array}{l}0.02 \pm 0.27 \\
-0.32 \text { to } 0.63\end{array}$ \\
\hline & $\hat{r}_{p}$ & $\begin{array}{l}-0.06 \pm 0.16 \\
-0.32 \text { to } 0.21\end{array}$ & $\begin{array}{l}-0.48 \pm 0.12 \\
-0.64 \text { to }-0.23\end{array}$ & $\begin{array}{l}-0.20 \pm 0.14 \\
-0.45 \text { to } 0.03\end{array}$ & $\begin{array}{l}0.38 \pm 0.06 \\
0.30 \text { to } 0.48\end{array}$ & $\begin{array}{l}-0.01 \pm 0.40 \\
-0.60 \text { to } 0.60\end{array}$ & $\begin{array}{l}0.14 \pm 0.13 \\
0.02 \text { to } 0.47\end{array}$ \\
\hline
\end{tabular}

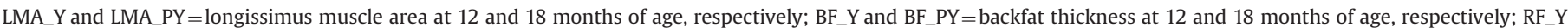
and RF_PY =rump fat thickness at 12 and 18 months of age, respectively; $\mathrm{AFC}=$ age at first calving; $\mathrm{FCI}=$ first calving interval.

a Posterior mean \pm standard deviation

b $95 \%$ high posterior density interval

the structure of the data file after the confirmation of consistency. The relationship matrix included animals until the last generation known and comprised a total of 69,872 animals.

\subsection{Analysis}

The (co)variance components were estimated by multiple trait analysis under an animal model using the GIBBS2F90 program developed by Misztal et al. (2002), which was written in the Fortran 90 language and is based on Bayesian inference using the Gibbs sampler. Non-informative or flat distributions (not reflecting previous knowledge of the parameter) were used for a priori estimates of additive and residual (co)variances, which the program transforms into a proper distribution. A uniform a priori distribution was assumed for systematic effects and an inverse Wishart distribution was assumed for the other components.

First, a chain of 1,500,000 iterations was computed. The final chain size, burn-in period and sampling interval (thin) were defined using the criterion of Raftery and Lewis (1992), which indicates convergence of the chain based on a low serial correlation between cycles, and the criterion of Gelman and Rubin (1992). These analyses were performed using the Bayesian Output Analysis (BOA) package of the R program (Anon., 2008). In addition to these criteria, the convergence of the Gibbs chain was also evaluated by visual inspection of the parameters using dispersion graphs. After evaluation of the convergence of the Gibbs chain, the posterior distribution estimates were calculated after discarding 600,000 initial iterations, then using a sampling interval of 12 iterations, corresponding to 75,000 samples for the estimation of the mean, standard deviation, median, mode, Monte Carlo error, effective sample size, and 95\% high posterior density interval (HPD). The Bayesian Output Analysis and Output Analysis and Diagnostics for MCMC (CODA) (Plummer et al., 2006) packages of the $\mathrm{R}$ program were used for this purpose.

The models used for all traits included direct additive genetic and residual effects as random effects, systematic effects of CG, and age of the animal as covariate (linear and quadratic effects, except for SC450 and AFC). FCI was analyzed using the same model, which additionally included the systematic effect of the breeding method (insemination or natural breeding) for second pregnancy. For BF, RF, weight (all obtained at 12 and 18 months of age) and $\mathrm{HH}$, the systematic effect of age of dam at calving, divided into six classes $(35 ; 36-47 ; 48-59 ; 60-71 ; 72-119$, and $>120$ months), was also included.

The general model used is: $\underset{\sim}{\mathbf{y}}=\mathbf{X} \underset{\sim}{\beta}+\mathbf{Z}_{\sim}^{a}+\underset{\sim}{\mathrm{e}}$, where $\underset{\sim}{\mathrm{y}}$ is the vector of observations; $\underset{\sim}{\beta}$ is the vector of unknown systematic effects; a is the vector of unknown random effects that correspond to the additive breeding values of each animal; $\underset{\sim}{e}$ is the vector of unknown random residual effects, and $\mathbf{X}$ and $\mathbf{Z}$ are incidence matrices that associate the records with fixed and random additive genetic effects, respectively. The assumptions of the distribution of $\underset{\sim}{\mathrm{y}}, \underset{\sim}{\mathrm{a}}$ and $\underset{\sim}{e}$ can be described as $\underset{\sim}{\mathrm{y}} \sim \mathrm{N}\left(\mathbf{X} \underset{\sim}{\beta}+\mathbf{Z} \underset{\sim}{\mathrm{a}}, \mathrm{I} \sigma_{\mathrm{e}}^{2}\right), \mathrm{p}\left(\underset{\sim}{\mathrm{a}} \mid \sigma_{a}^{2}\right) \sim \mathrm{N}(0, \mathrm{~A} \otimes \mathrm{G})$, and $\mathrm{p}\left(\mathrm{e}_{\sim} \sigma_{e}^{2}\right) \sim N\left(0, \mathrm{I} \sigma_{e}^{2}\right)$, where $\mathbf{A}$ is the numerator matrix of Wright's coefficient of relationship between animals; $\mathbf{I}$ is the identity matrix of the same order as $\underset{\sim}{\mathrm{y}}$; $\mathbf{G}$ is the additive genetic variance-covariance matrix between traits, and $\sigma_{a}^{2}$ and $\sigma_{e}^{2}$ are additive genetic and residual variances, respectively.

\section{Results and discussion}

The posterior mean, median and mode of all parameters estimated were similar (data not shown), indicating symmetric marginal distributions. The Monte Carlo errors were low and the effective sample sizes were high ( $>300$ for all parameters studied; statistical data not shown). The results of the descriptive posterior marginal distributions indicate the reliability of the parameters estimated and convergence of the analyses. Therefore, the heritabilities and correlations were estimated by the use of the mean as a criterion satisfactorily representing the property of this parameter and properly reflecting the measure of central tendency of its posterior marginal distribution. Tables 2 and 3 show the mean, standard deviation and HPD interval of heritabilities and genetic and phenotypic correlations between the traits studied.

The heritability estimates for the carcass traits measured by ultrasound at the two ages ( $\mathrm{Y}$ and PY) were of moderate to high magnitude, with estimates ranging from 0.33 to 0.60 (Table 2), indicating that variations in these traits are mainly due to genes of additive action. Thus, selection for these traits is an effective tool to obtain genetic changes in the population. Considering that a moderate heritability estimate ranges from 0.20 to 0.39 and high heritability is defined as a value $>0.40$ (Bourdon, 1997), as can be seen in Fig. 1, most heritabilities estimated for the ultrasound carcass traits, except for LMA_PY and BF_Y, were high, i.e., above this threshold $(0.40)$. The heritability estimates for the ultrasound carcass traits suggest that, even when these traits are measured at ages close to yearling, Nellore animals can be selected efficiently.

Higher yearling heritabilities were estimated for LMA, indicating that better responses to selection can be expected when this trait is measured at yearling age. On the other hand, BF presented a higher heritability estimate at 18 months of age, probably because of its later deposition as reported by Yokoo et al. (2008) and of environmental effects that prevent its anticipated expression in tropical regions. With respect to RF, selection at the two ages will 


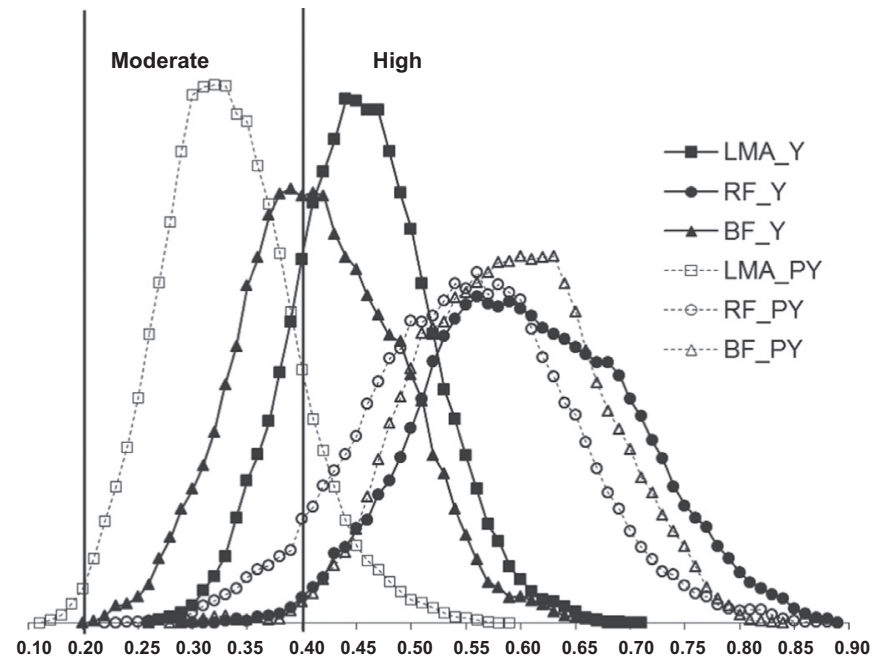

Fig. 1. Marginal posterior density of the heritability estimates for carcass traits measured by ultrasound at 12 and 18 months of age, together with the criterion of moderate to high magnitudes suggested by Bourdon (1997).

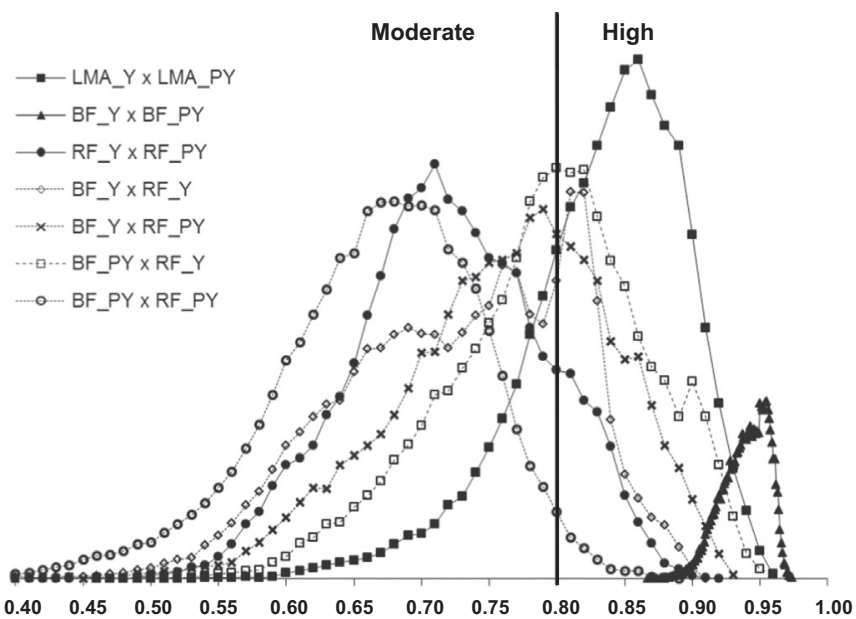

Fig. 2. Marginal posterior density of the genetic correlations between carcass traits measured by ultrasound at 12 and 18 months of age, together with the criterion of high correlations suggested by Robertson (1959).

result in rapid genetic gains since heritability estimates are high at both yearling and 18 months of age.

As can be seen in Fig. 2, most genetic correlations between the same carcass traits measured by ultrasound at yearling and at 18 months of age and between the different subcutaneous fat thickness traits, except for the correlation between RF_Y and RF_PY and between BF_PY and RF_PY, were high $(>0.80)$, indicating that the two traits can be considered to be practically the same. Robertson (1959) suggested that, when the genetic correlation between two traits is higher than 0.80 , only one of the traits should be included in selection programs or in the selection index.

The posterior point estimates (mean) of genetic correlations between carcass traits obtained at $\mathrm{Y}$ and at PY of age (LMA_Y $\times$ LMA_PY, BF_Y $\times$ BF_PY and RF_Y $\times$ RF_PY) were of high magnitude (0.72-0.94), indicating that a large part of the same sets of genes of additive action act on the expression of these traits. The 95\% HPD interval of the correlation between BF_Y and BF_PY (0.91-0.97) indicates that these traits are practically the same. In addition, as can be seen in Fig. 2, the marginal posterior density of this parameter is completely beyond the criterion suggested by Robertson (1959), which is 0.80. Regarding the correlation between LMA_Y and LMA_PY, the HPD interval ranged from 0.71 to
0.94 , with most of the marginal posterior density of this parameter being higher than 0.80 (Fig. 2). However, the HPD interval of the correlation between RF_Y and RF_PY was lower, ranging from 0.57 to 0.84 , suggesting that the genes responsible for the expression of this trait may change with age.

The genetic correlations between BF and RF obtained at $\mathrm{Y}$ and at PY of age were high, with the posterior point estimates ranging from 0.67 to 0.79 . Thus, only one subcutaneous fat measure (BF or $\mathrm{RF}$ ) obtained at only one age (Y or PY) might be sufficiently useful as a selection criterion. As can be seen in Fig. 2, the higher density of these correlations is found above to 0.70, especially for the correlation between BF_Y $\times$ RF_Y, BF_Y $\times$ RF_PY and BF_PY $\times$ RF_Y. The lowest correlation was observed between BF_PY $\times$ RF_PY (HPD of 0.51-0.81), a finding that can be explained by the late deposition of subcutaneous fat in the ribs when compared to rump fat deposition. Nevertheless, these correlations indicate that selection for any of these traits should lead to rapid genetic gains in the other subcutaneous fat traits due to a correlated response. In the case of production systems of super-precocious heifers in tropical regions designed to slaughter the animals at about one year of age with good carcass finishing, the use of RF_Y as a selection criterion may increase genetic gains when compared to the gains obtained with BF_Y, BF_PY or even RF_PY. These results are interesting and of practical relevance since evaluations of carcass traits for the quantification of finishing would be faster and less expensive if performed at yearling age and if only RF is evaluated. Furthermore, the breeders could select and discard animals in younger ages, since the heritability for LMA_Y and others growth and reproductive traits are moderate to high magnitudes at yearling age.

The estimated genetic correlations between $\mathrm{BF}$ and $\mathrm{RF}$ agree with those reported in the literature for taurine breeds studied at ages close to yearling (Reverter et al., 2000; Kemp et al., 2002; Stelzleni et al., 2002), for Nellore animals studied at 18 months of age using part of the present data (Yokoo et al., 2008; Caetano et al., 2013) and for Guzera animals studied at 18 months of age (Lima Neto et al., 2009).

The heritability estimates and genetic correlations between ultrasound carcass traits indicate that selection could be performed using younger animals, i.e., at about one year of age, with the genetic gain being comparable to that obtained at 18 months of age, especially when the animals are selected for LMA and RF. This sentence would be strengthened by specifically demonstrating the correlated response in post yearling rump fat per $i$ (selection intensity) of selection on yearling rump fat. Furthermore, at younger ages the selection intensity is probably higher compared to older ages where the breeders have fewer animals (i.e., discard, sale and death). However, the ideal age at which selection for these traits should be performed depends on each production system since the most appropriate season for measuring the animals also depends on management and on economic factors of the production system. For example, on some properties the period of carcass data collection may coincide with the breeding season. In this case, the simultaneous execution of data collection by ultrasound and breeding may negatively interfere with the incidence of heifer pregnancy.

The posterior point estimates of the genetic correlations between LMA (Y and PY of age) and the two fat thickness measures (BF and RF at Y and PY of age) were low and close to zero. In addition, the HPD interval included zero, with this value being close to be a central measure, indicating that these traits are independent, i.e., they are determined by different sets of genes of additive action. As a consequence, selection for higher LMA ( $Y$ and PY of age) will not result in a correlated response of BF or RF at Y and PY of age. These results agree with those reported by different investigators studying taurine (Reverter et al., 2000; Kemp et al., 
2002; Stelzleni et al., 2002) and zebu breeds (Yokoo et al., 2008; Lima Neto et al., 2009; Caetano et al., 2013).

Weights at different ages showed moderate positive genetic correlations with BF_Y (0.47-0.53). These results were not expected and differ from those reported by Waldner et al. (1992) and Shepard et al. (1996), who estimated correlations close to zero. However, Stelzleni et al. (2002), studying approximately 1200 Brangus animals at ages of 320-410 days, found a genetic correlation between BF_Y and yearling weight similar to that observed in the present study (0.42). Therefore, further studies including maternal effects on BF_Y are necessary, which was not possible in the present study because of the data structure. On the other hand, the correlations between weights and the other fat thickness measures (BF_PY, RF_Y and RF_PY) were low (0.07-0.24), indicating that if the selection objective includes weight and subcutaneous fat thickness, both traits must be used as selection criteria, especially when selection is performed at 18 months of age. The literature reports genetic correlations between weight at different ages and fat measures (subcutaneous and intramuscular fat thickness) close to those estimated in the present study for BF_PY, RF_Y and RF_PY, ranging from -0.05 to 0.19 (Shepard et al., 1996; Moser et al., 1998; Meyer et al., 2004).

Analysis of the genetic correlations between subcutaneous fat thickness measures and $\mathrm{HH}$ showed a moderate positive correlation with BF_Y $(0.27 \pm 0.17)$, a correlation close to zero with RF_Y $(-0.17 \pm 0.15)$, and moderate negative correlations with BF_PY and RF_PY $(-0.38 \pm 0.12$ and $-0.32 \pm 0.05$, respectively). These correlations indicate that selection for animals with high carcass finishing scores at 18 months of age would lead to smaller animals at this age. The moderate positive correlation between $\mathrm{HH}$ and BF_Y, indicating that at yearling age Nellore animals in tropical areas should improve the weight, as discussed before. Waldner et al. (1992) estimated genetic correlations between HH and BF_Y close to zero $(-0.07)$ for animals reared in temperate regions. Similarly, Riley et al. (2002), studying carcass traits in Brahman animals measured directly in the carcass, also obtained genetic correlations between BF_Y and HH close to zero.

The genetic correlations between the subcutaneous fat thickness measures (except for BF_Y) and SC450 were close to zero ( -0.02 to 0.12 ). These results agree with Meyer et al. (2004) who reported correlations of $0.02-0.09$ for Hereford animals. Since SC450 is used as an indicator trait of sexual precocity and the phenotypic relationships between subcutaneous fat thickness and scrotal circumference are favorable (Lima et al., 2011), it would be expected that animals that mature earlier in terms of carcass finishing are also sexually more precocious. As a consequence, a positive (favorable) genetic correlation between SC450 and subcutaneous fat thickness would be expected, which was not confirmed for the measures obtained at 18 months of age and for RF_Y. However, at younger ages, BF_Y showed a moderate positive genetic correlation with SC450 $(0.40 \pm 0.17)$. Favorable genetic correlations, although of moderate to low magnitude, have been reported by Meyer and Johnston (2003) and Meyer et al. (2004) who studied the relationship between female reproductive traits, days to calving and fat (subcutaneous and intramuscular) in Hereford cattle. For Nellore animals, Caetano et al. (2013) showed favorable genetic correlation between age of first calving and subcutaneous fat thickness measures of -0.35 and -0.19 , respectively for BF_PY and RF_PY.

The genetic correlations between LMA (yearling and 18 months of age) and weights (yearling and 18 months of age) were of moderate to high magnitude, ranging from 0.57 to 0.65 . In contrast, the correlations between LMA (yearling and 18 months of age) and HH were low (close to zero), ranging from 0.18 to 0.22 . Similar genetic correlation estimates between LMA and weights at different ages and $\mathrm{HH}$ have been reported in the literature
(Waldner et al., 1992; Shepard et al., 1996; Meyer et al., 2004). These results indicate that selection for weight at any of these ages should lead to an increase in LMA measured at 12 and 18 months of age. In addition, the use of LMA as a selection criterion should not affect the growth trait $\mathrm{HH}$ in the medium or long term due to a correlated response. In other words, increasing the frame size without account the LMA in the selection index will probably decrease the yield of carcass and commercial cuts in Nellore cattle.

The genetic correlations between LMA at yearling and at 18 months of age and SC450 were of low to moderate magnitude, ranging from 0.20 to 0.32 . Low to moderate positive genetic correlations between LMA and SC have also been reported by Turner et al. (1990) for Hereford animals, by Johnson et al. (1993) for Brangus cattle, and by Meyer et al. (2004) for Hereford cattle (0.49, 0.19 and 0.13 , respectively). Since SC450 is strongly associated with growth (Yokoo et al., 2007), animals with higher SC450 would be expected to be more muscular due to favorable genetic correlation between LMA and weight. However, these outcomes suggest that selection for SC450 will not result in an expressive correlated response for LMA and vice-versa.

Table 3 shows the correlations between ultrasound carcass traits and FCI and AFC. The genetic correlations between FCI and the ultrasound carcass traits, except for BF_PY $(0.40 \pm 0.17)$, did not differ from zero. These results indicate that selection aimed at reducing FCI will decrease subcutaneous fat thickness in the region of the ribs at 18 months of age despite the low heritability for FCI $(0.11 \pm 0.03)$, but will not affect muscling due to a correlated response. However, conflicting results have been reported by Meyer and Johnston (2003) and Meyer et al. (2004) who found negative genetic correlations of moderate to low magnitude between female reproductive traits, days to calving and intramuscular and subcutaneous fat thickness in Hereford cattle.

The posterior means of the genetic correlations between the ultrasound carcass traits and AFC were low (close to zero). In addition, all HPD intervals ranged from negative to positive values, i.e., they included zero more frequently. These results suggest that more precocious animals selected based on AFC do not necessarily present higher subcutaneous fat deposition in the carcass or greater muscling at 18 months of age. Since the ovulation rate of females is regulated by a positive body energy balance (Bronson and Manning, 1991), it would be expected that animals that mature earlier in terms of carcass finishing are also sexually more precocious. However, in the present study FIC was unfavorably genetically associated with BF_PY $(0.40 \pm 0.17)$ and AFC was not

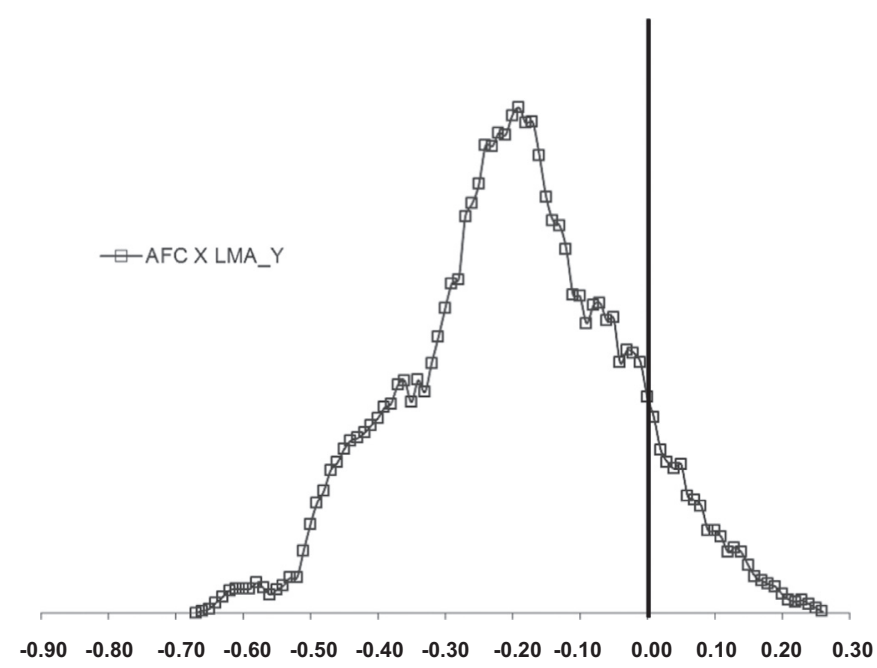

Fig. 3. Marginal posterior density of the genetic correlation between age at first calving (AFC) and longissimus muscle area at yearling (LMA_Y). 
genetically correlated with subcutaneous fat thickness. The phenotypic correlation estimates showed the same trend as the genetic correlations, but were lower (Table 3 ).

Fig. 3 shows that most density values of the genetic correlation between AFC and LMA_Y were lower than zero, indicating that this association is most likely negative, although of low magnitude $(-0.20 \pm 0.16)$. In other words, increasing muscle by selection of LMA_Y should produce heifers more precocious in terms of reproduction in Nellore cattle due to a correlated response.

\section{Conclusions}

The carcass traits measured by ultrasound at yearling and at 18 months of age should respond rapidly to individual selection. The traits longissimus muscle area or backfat thickness measured at yearling and at 18 months of age are practically the same traits measured at the two ages, as they are controlled by the same set of genes. There is no need to include the two subcutaneous fat thickness measures (BF and RF) in selection indices because of the high genetic correlation between these traits. In this respect, the results of the present study demonstrated the possibility of selecting animals for better carcass finishing at yearling or at 18 months of age using only the traits measured by ultrasound as a selection criterion in one age. Long-term selection for increased subcutaneous fat thickness in the carcass at 18 months of age should reduce the height of animals due to a correlated response. Genetic progress in carcass traits measured by ultrasound at yearling and 18 months of age can be achieved without compromising the breeding value of animals for weight and scrotal circumference, since long-term selection for higher weight at yearling or at 18 months of age should lead to an increase in longissimus muscle area due to a correlated response. Selection for lower age at first calving of Nellore females will not affect subcutaneous fat deposition in the carcass or muscling, despite the favorable genetic correlation between age at first calving and longissimus muscle area at 12 months of age. Long-term selection for ultrasound-measured carcass traits, except for backfat thickness at 18 months of age, will not affect first calving interval due to a correlated response. Genetic progress in these carcass traits measured by ultrasound at yearling and at 18 months of age can be achieved without affecting the breeding value of animals for other important traits, when an appropriated selection index is developed.

\section{Conflict of Interest}

We do not have any Conflict of Interest.

\section{Acknowledgements}

This research was funded by the National Council for Scientific and Technological Development of Brazil.

\section{References}

Beef Improvement Federation (BIF), 1996. Guidelines For Uniform Beef Improvement Programs, 7th ed. Kansas State University, Colby, Kansas, USA.

Beef Improvement Federation, 2002. Guidelines For Uniform Beef Improvement Programs, 8th ed. University of Georgia, Athens, Georgia, USA.

Bourdon, R.M., 1997. Understanding Animal Breeding. Prentice Hall, New Jersey, p. 523.

Bronson, F.H., Manning, J.M., 1991. The energetic regulation of ovulation: a realistic role for body fat. Biol. Reprod. 44, 945-950.
Caetano, S.L., Savegnago, R.P., Boligon, A.A., Ramos, S.B., Chud, T.C.S., Lôbo, R.B., Munari, D.P., 2013. Estimates of genetic parameters for carcass, growth and reproductive traits in Nellore cattle. Livest. Sci. 155, 1-7.

Gelman, A., Rubin, D.B., 1992. Inference from iterative simulation using multiple sequences. Stat. Sci. 7, 457-511.

Hassen, A., Wilson, D.E., Rouse, G.H., Tait Jr., R.G., 2004. Partitioning variances of growth in ultrasound longissimus muscle area measures in Angus bulls and heifers. J. Anim. Sci. 82, 1272-1279.

Herring, W.O., Kriese, L.A., Bertrand, J.K., Crouch, J., 1998. Comparison of four realtime ultrasound systems that predict intramuscular fat in beef cattle. J. Anim. Sci. 76, 364-370.

Johnson, M.Z., Schalles, R.R., Dikeman, M.E., Golden, B.L., 1993. Genetic parameter estimates of ultrasound-measured longissimus muscle area and 12th rib fat thickness in Brangus cattle. J. Anim. Sci. 71, 2623-2630.

Kemp, D.J., Herring, W.O., Kaiser, C.J., 2002. Genetic and environmental parameters for steer ultrasound and carcass traits. J. Anim. Sci. 80, 1489-1496.

Lima Neto, H.R., Bergmann, J.A.G., Gonçalves, T.M., Araujo, F.R.C., Bezerra, L.A.F., Sainz, R.D., Lôbo, R.B., Silva, M.A., 2009. Parâmetros genéticos para características de carcaça avaliadas por ultrassonografia em bovinos da raça Guzerá. Arq. Bras. Med. Vet. Zootec. 61, 251-258.

Lima, F.P.C., Bergmann, J.A.G., Xavier, P.R., Marques Jr, A.P., 2011. Zootecnic characteristics of Nelore bulls subjected to a selection program for sexual precocity Arq. Bras. Med. Vet. Zootec. 63, 1303-1308.

Meyer, K., Johnston, D.J., 2003. Estimates of genetic correlations between live ultrasound scan traits and days to calving in Hereford cattle. In: Proceeding of the 15th Association for the Advancement of Animal Breeding and Genetics, 06-11 July 2003, Melbourne, Australia, pp. 387-390.

Meyer, K., Johnston, D.J., Graser, H.U., 2004. Estimates of the complete genetic covariance matrix for traits in multi-trait genetic evaluation of Australian Hereford cattle. Aust. J. Agric. Res. 55, 195-210.

Misztal, I., Tsuruta, S., Strabel, T., Auvray, B., Druet, T., Lee, D.H., 2002. BLUPF90 and related programs (BGF90). In: Proceedings of the 7th World Congress of Genetics Applied to Livestock Production, 19-23 August 2002, Montpellier, France, CD-ROM.

Moser, D.W., Bertrand, J.K., Misztal, I., Kriese, L.A., Benyshek, L.L., 1998. Genetic parameter estimates for carcass and yearling ultrasound measurements in Brangus cattle. J. Anim. Sci. 76, 2542-2548.

NRC, 1996. Guide for the Care and Use of Laboratory Animals. Institute of Laboratory Animal Resources, Commission on Life Sciences, National Academy Press, Washington, DC, EUA.

Perkins, T.L., Green, R.D., Hamlin, K.E., 1992a. Evaluation of ultrasonic estimates of carcass fat thickness and longissimus muscle area in beef cattle. J. Anim. Sci. 70, 1002-1010

Perkins, T.L., Green, R.D., Hamlin, K.E., Shepard, H.H., Miller, M.F., 1992b. Ultrasonic prediction of carcass merit in beef cattle: evaluation of technician effects on ultrasonic estimates of carcass fat thickness and longissimus muscle area. J. Anim. Sci. 70, 2758-2765.

Plummer, M., Best, N., Cowles, K., Vines, K., 2006. Coda: output analysis and diagnostics for MCMC, R-project. Retrieved on 30 October 2009, from 〈http://rhmirror.linux.iastate.edu/CRAN/ $>$.

Anon., 2008, R: a language and environment for statistical computing. Vienna, Austria: R. Foundation for Statistical Computing, Retrieved on 10 October 2008 from 〈http://www.R-project.org/〉.

Raftery, A.E., Lewis, S.M., 1992. Comment: one long run with diagnostics: implementation strategies for Markov chain Monte Carlo. Stat. Sci. 7, 493-497.

Reverter, A., Johnston, D.J., Graser, H.U., Wolcott, M.L., Upton, W.H., 2000. Genetic analyses of live animal ultrasound and abattoir carcass traits in Australian Angus and Hereford cattle. J. Anim. Sci. 78, 1786-1795.

Riley, D.G., Chase Jr., C.C., Hammond, A.C., West, R.L., Johnson, D.D., Olson, T.A., Coleman, S.W., 2002. Estimated genetic parameters for carcass traits of Brahman cattle. J. Anim. Sci. 80, 955-962.

Robertson, A., 1959. The sampling variance of the genetic correlation coefficient Biometrics 15, 469-485.

Shepard, H.H., Green, R.D., Golden, B.L., Hamlin, K.E., Perkins, T.L., Diles, J.B., 1996. Genetic parameter estimates of live animal ultrasonic measures of retail yield indicators in yearling breeding cattle. J. Anim. Sci. 74, 761-768.

Stelzleni, A.M., Perkins, T.L., Brown Jr, A.H., Pohlman, F.W., Johnson, Z.B., Sandelin, B. A., 2002. Genetic parameter estimates of yearling live animal ultrasonic measurements in Brangus cattle. J. Anim. Sci. 80, 3150-3153.

Turner, J.W., Pelton, L.S., Cross, H.R., 1990. Using live animal ultrasound measures of ribeye area and fat thickness in yearling Hereford bulls. J. Anim. Sci. 68, 3502-3506.

Waldner, D.N., Dikerman, M.E., Schalles, R.R., Olson, W.G., Houghton, P.L., Unrush, J. A., Corah, L.R., 1992. Validation of real-time ultrasound technology for predicting fat thickness, longissimus muscle areas and composition of Brangus bulls from 4 months to 2 years age. J. Anim. Sci. 70, 973-983.

Wilson, D.E., Willham, R.L., Northcutt, S.L., Rouse, G.H., 1993. Genetic parameters for carcass traits estimated from Angus field records. J. Anim. Sci. 71, 2365-2370.

Wilson, D.E., 1992. Application of ultrasound for genetic improvement. J. Anim. Sci. 70, 973-983.

Yokoo, M.J., Albuquerque, L.G., Lobo, R.B., Bezerra, L.A.F., Araujo, F.R.C., Silva, J.A.V. Sainz, R.D., 2008. Genetic and environmental factors affecting ultrasound measures of longissimus muscle area and backfat thickness in Nelore cattle. Livest. Sci. 117, 147-154.

Yokoo, M.J., Albuquerque, L.G., Lobo, R.B., Sainz, R.D., Carneiro Júnior, J.M., Bezerra, L.A.F., Araujo, F.R.C., 2007. Estimativas de correlações genéticas entre altura do posterior, peso e circunferência escrotal em bovinos da raça Nelore. Rev. Bras. 